\title{
Opiniones \\ sobre Carmen Luisa Letelier Valdés
}

La Revista Musical Chilena ha recogido opiniones de una serie de personalidades de la cultura, especialmente de la música, a propósito del Premio Nacional de Arte mención Música 2010, recibido por la intérprete y académica de la Universidad de Chile y de la Academia de Bellas Artes del Instituto de Chile, profesora Carmen Luisa Letelier Valdés. A continuación se transcriben algunas de ellas.

****

Carlos Aldunate del Solar, Director Museo Chileno de Arte Precolombino, miembro de número de la Academia Chilena de la Historia, presidente de la Corporación Patrimonial Cultural, manifestó:

"La señora Letelier, destacadísima contralto chilena, proveniente de una brillante familia de músicos chilenos, entre los cuales están los premios nacionales Alfonso y Miguel Letelier, a juicio del suscrito tiene méritos personales más que suficientes para haber recibido la mencionada distinción. Su calidad y rigurosidad musical y su extraordinario timbre vocal le ha permitido un nutrido repertorio de autores clásicos y modernos en diversos géneros musicales, tales como ópera, lied, música de cámara, oratorios, etc.

Fuera de ello, destaco su determinada vocación por la difusión de música americana y especialmente chilena, desde la Colonia hasta hoy. Esta labor la ha desarrollado tanto en su repertorio que ha presentado dentro y fuera del país y también a través de la constitución del Ensemble Bartok del cual ha sido fundadora e intérprete, conjunto de gran gestión y calidad que se ha destacado por difundir este mismo repertorio, dando a conocer la música chilena y americana a distintos públicos chilenos y extranjeros. Fuera de lo expuesto destaco también su labor como docente de la Universidad de Chile, que ha formado a generaciones de músicos chilenos. Todo ello hace de Carmen Luisa Letelier una destacadísima música chilena con méritos más que suficientes para prestigiar este galardón”.

Eduardo Cáceres Romero, compositor-académico, Premio Altazor, Medalla de la Música Unesco, subdirector del Departamento de Música y Sonología de la Facultad de Artes, Universidad de Chile, expresa: 
"La artista ha desarrollado una extensa trayectoria nacional e internacional integrando diversas agrupaciones de cámara en donde se destaca su participación por décadas en el renombrado conjunto Ensemble Bartok.

La cantante y académica siempre ha estado interesada en dar a conocer la música de concierto de los compositores chilenos así como también la música clásica de los grandes maestros internacionales de todas las épocas.

Su registro de contralto la hace única en su color vocal destacándose por su timbre cálido y consistente, versátil y convincente hasta el día de hoy”.

Mario Córdova Pérez, Crítico de Música y Ópera, diario La Época (1991-1998); diario Las Últimas Noticias (desde 1998), manifiesta:

"Considero de toda justicia no haber seguido esperando el paso del tiempo para premiar a Carmen Luisa Letelier Valdés, quien ha desarrollado una vida entera consagrada al canto tanto en los escenarios como en las aulas.

Impresiona muy gratamente constatar cómo ella ha destacado en la ópera, la canción, el oratorio, la música antigua y también la permanente difusión de los compositores chilenos, a la vez que en lo pedagógico ha formado a muchos valores que hoy destacan en los más variados ámbitos.

He seguido la magnífica carrera de la señora Letelier por más de tres décadas, las dos últimas desde mi tribuna de crítico musical, y considero de toda justicia que haya recaído en ella el Premio del año 2010”.

Rolando Cori Traverso, Académico del Departamento de Música y Sonología de la Facultad de Artes de la Universidad de Chile y miembro del Senado Universitario, expresó:

"Destaco su trayectoria artística que le ha merecido presentarse en algunos de los más prestigiosos escenarios de Latinoamérica (Teatro Colón de Buenos Aires), Estados Unidos (Carnegie Hall) y Europa. En referencia a su oficio profesional resalto su versatilidad para abordar un repertorio de la más diversa índole que comprende el género barroco, la ópera, el lied, y la música contemporánea de la cual no quedan excluidas incursiones en el repertorio de raíz popular y folclórico.

Un segundo aspecto se refiere a la escuela de talentos que ha formado. En su cátedra de canto en la Universidad de Chile han surgido numerosas figuras de relieve que actualmente están iniciando perfeccionamiento y carrera en Europa, como Carolina Grammelstorff y Juan Dupré, entre otros.

En especial es en la difusión de la cultura chilena en que -a mi juicio- esta artista hace su aporte superlativo. Su prodigiosa capacidad de aprender nuevos y exigentes repertorios junto a una motivación permanente por dar a conocer tanto las obras de los creadores chilenos consagrados como también la de los jóvenes que exhiben sus primeras composiciones, hacen de Carmen Luisa Letelier por lejos la cantante lírica que más ha difundido la música de compositores chilenos tanto en nuestro país como en el extranjero". 
Dr. Alejandro Goic G., Presidente de la Academia Chilena de Medicina, expresa:

"El Estado chileno concede el Premio Nacional de Arte a quienes muestran una trayectoria destacada en cualquiera de las expresiones artísticas y han contribuido con su dedicación al enriquecimiento cultural y espiritual de la nación. A mi parecer, en el campo de las artes musicales, la profesora Carmen Luisa Letelier Valdés ha desarrollado una distinguida y prolongada carrera profesional y académica en Chile y en el extranjero como intérprete superior en canto, así como en la docencia universitaria. Los numerosos premios y distinciones que ha recibido avalan su trayectoria profesional y su extraordinaria calidad vocal.

La profesora Letelier, además de cultivar el canto lírico, se ha destacado por promover, a través de su arte, antiguas y valiosas expresiones del folclore nacional, mediante conciertos, encuentros y ceremonias, en una excepcional labor de extensión cultural y artística, poniendo de relieve antiguas manifestaciones musicales de nuestro país. Además, en su tarea universitaria como profesora titular de la Universidad de Chile ha formado numerosos discípulos en el arte vocal, que han proyectado en el tiempo la permanencia y perfeccionamiento de esta singular disciplina.

En razón de lo anterior, tengo la convicción de que la profesora Carmen Luisa Letelier Valdés ha recibido merecidamente este reconocimiento por su destacada trayectoria a favor del arte musical y la cultura".

Juan Antonio Muñoz H., editor diario El Mercurio. Crítico de ópera, manifestó:

"Contralto de trayectoria, Carmen Luisa Letelier ha dedicado su vida a la interpretación y a la enseñanza del canto. Es difícil que una artista pueda compatibilizar ambos aspectos sin nunca postergar uno en beneficio del otro. Ella lo ha hecho, como dan testimonios los cientos de obras que ha interpretado en Chile y en el extranjero, y a los numerosos jóvenes que han estudiado en su aula en la Facultad de Artes de la Universidad de Chile.

Su repertorio es amplísimo, e incluye obras del Renacimiento y el Barroco temprano hasta partituras del siglo XXI. Como miembro del Ensemble Bartok su trabajo ha sido de gran relevancia pues con este conjunto ha estrenado cientos de obras de escasa difusión e importantísimas para el acervo musical internacional. Son incontables las piezas de compositores chilenos que han sido estrenadas por ella.

No se puede olvidar su labor en el mundo de los oratorios, en la ópera y, especialmente, en el campo del Lied, género que requiere de fina sensibilidad y de una musicalidad a toda prueba.

Artista estudiosa e intérprete expresiva. Dueña de un material vocal personalísimo, es una de las grandes cantantes de la historia de Chile, y de las pocas que con tanta dedicación ha abordado la música contemporánea y la enseñanza”.

$* * *$

Luis Orlandini Robert, director del Departamento de Música y Sonología de la Facultad de Artes de la Universidad de Chile, expresa: 
"La profesora Letelier ha llevado a cabo durante su vida una dedicación irrestricta al arte, y en especial a la música, como contralto, ofreciendo una cantidad innumerable de conciertos, recitales, actuaciones en óperas y oratorios, además de una importantísima labor formadora de cantantes en nuestro país al más alto nivel artístico. Es especialmente encomiable también, la fecunda labor que ha realizado para difundir la música de los creadores chilenos actuales tanto en nuestro país como en importantes salas de conciertos de todo el mundo. Su labor con el Ensemble Bartok, en esta misma línea, le permitió cultivar con maestría la música de cámara, especialmente de la música contemporánea.

Tenemos el convencimiento de que la profesora Letelier, más allá de haber recibido numerosos premios y distinciones en su carrera artística, es ampliamente merecedora de este premio, el máximo galardón que nuestro país otorga a sus artistas”.

Pablo Oyarzún Robles, ex Decano de la Facultad de Artes de la Universidad de Chile:

"Conozco a Carmen Luisa desde hace largo tiempo, como colega en la Facultad de Artes de la Universidad de Chile y, por cierto, como una de las más destacadas intérpretes nacionales en la disciplina del canto, habiéndome beneficiado, junto a tantas otras personas, del regalo de sus dotes musicales.

Ella reúne, a mi entender, todos los requisitos para hacerse sobradamente merecedora de esta alta distinción, tanto desde el punto de vista de su trayectoria artística como intérprete, en el ámbito nacional e internacional, iniciada hace ya más de cuarenta años, como en virtud de su calidad de formadora de nuevas generaciones de cultores del canto lírico.

Creo oportuno destacar particularmente su constante preocupación y su dedicación incansable al fomento y difusión de la música de los compositores chilenos, a través de múltiples iniciativas: conciertos, giras internacionales, grabaciones, encargos, artículos y foros.

Del mismo modo ha de valorarse su labor de tres décadas consagrada a la docencia y formación de cantantes, con apreciable sensibilidad e inteligencia, y, desde luego, con la satisfacción renovada de ver nacer y desarrollarse nuevos artistas que lucen sus talentos en escenarios del país y del extranjero, y que le agradecen haber sido quien supo llevarlos a la plenitud de sus capacidades a través de la enseñanza tenaz, el rigor, la disciplina y la cercanía afectuosa.

Estoy persuadido de que el otorgamiento del Premio Nacional de Arte mención Música entraña un justísimo reconocimiento a una de nuestras artistas sobresalientes".

\section{Marino Pizarro Pizarro, ex Rector de la Universidad de Chile manifiesta:}

"Los merecimientos de la académica son sobradamente conocidos en el medio artístico nacional, toda vez que desde muy temprano se destacó como solista en nuestro Teatro Municipal, y en multitud de eventos, nacionales y extranjeros. Las plazas del 
Salón Dorado del Teatro Colón, de Buenos Aires; del Museo de la Literatura Polaca de la Universidad Jagellona en Cracovia; de la Academia de Música, en Praga, y a través de los conciertos del Ensemble Bartok, visitando el Carnegie Hall, en Nueva York, Estados Unidos de América, demuestran palmariamente sus capacidades interpretativas.

Ha recibido, previamente, variados premios, como el de la Crítica de Uruguay, por su interpretación de Das Lied von der Erde, de Mahler (1978), el Domingo Santa Cruz, de la Academia Chilena de Bellas Artes, del Instituto de Chile (1999) y dos veces el Altazor, por su participación en los conciertos del Ensemble Bartok (2000) y en la ópera Madama Butterfly (2001)".

\section{Walter Krumbach K., Productor Radio Universidad de Santiago, expresa:}

"La señora Letelier tiene a su haber una vasta y fructífera trayectoria en el ámbito de la interpretación musical, como también en la formación de nuevos valores.

Su carrera de cantante es -en el ámbito nacional- una de las más descollantes de los últimos decenios. A sus condiciones naturales fuera de lo común suma una constante preocupación por la fidelidad a autores y estilos. Cultiva un variado repertorio, desde el barroco hasta la época contemporánea, tanto en ópera, oratorio, lied y otros géneros, siempre con el acierto y la autoridad que entregan el talento y el conocimiento profundo de la materia a tratar.

La señora Letelier le ha asignado una particular importancia al repertorio chileno en sus presentaciones, que incluyó en sus recitales durante toda su carrera de cantante. Así lo consignan, por lo demás, sus numerosas grabaciones de obras de compositores nacionales.

Por lo expuesto, estimo de justicia que una intérprete de excepción como la señora Carmen Luisa Letelier haya recibido el Premio Nacional de Arte mención Música”.

Andrés Rodríguez P., Director General del Teatro Municipal, Corporación Cultural de la Ilustre Municipalidad de Santiago, expresa:

"La señora Letelier ha participado por más de treinta años en innumerables producciones de ópera, recitales y conciertos sinfónicos en el Teatro Municipal de Santiago, en su registro de mezzo-soprano y contralto. Además, junto con el Ensemble Bartok, del cual forma parte, ha intervenido exitosamente en diversas presentaciones de música contemporánea.

La señora Carmen Luisa Letelier se ha caracterizado por ser una profesional altamente competente, desempeñándose con soltura en el campo de la lírica, la música sinfónica y la música contemporánea. Su trabajo ha sido siempre de un alto nivel de excelencia, constituyendo un verdadero aporte al desarrollo de la música y la ópera en Chile. Como maestra se ha destacado también en la enseñanza de la música, ofreciendo sus conocimientos a generaciones más jóvenes de cantantes. 
Sus grandes condiciones musicales, humanas, vocales, teatrales y pedagógicas constituyen un ejemplo para muchos artistas chilenos y representan una excelente contribución a la cultura musical de nuestro país".

$* * *$

Guillermo Scarabino, MA, decano de la Facultad de Artes y Ciencias Musicales de la Universidad Católica Argentina, expresa:

"Integrante de familia de músicos, formada con distinguidos maestros en la Universidad de Chile y mediante clases privadas, desde su juventud la licenciada Letelier Valdés ha participado de actividades artísticas del más alto nivel, con proyección internacional. Sus cualidades naturales, su formación cultural, vocal, musical y estilística, le han permitido realizar una brillante carrera, desarrollando un vastísimo repertorio que abarca exitosamente todos los géneros y épocas, desde la ópera y el oratorio a la canción de cámara, de la música medieval a la contemporánea, de la canción popular a la más exigente música académica. Especial mención requiere su dedicación a la difusión de la obra de compositores chilenos, que desde siempre ha ocupado prominente lugar en su repertorio.

Su titularidad de cátedra en la Universidad de Chile, su calidad de integrante del prestigioso Ensemble Bartok desde 1983, las veinticinco giras internacionales llevadas a cabo con este conjunto, su presencia habitual en los elencos del Teatro Municipal, las distinciones recibidas a lo largo de su carrera, constituyen logros que la hacen acreedora al más amplio reconocimiento".

$* * *$

Waldemar Sommer Tuñón, crítico de Arte y profesor universitario, expresa:

"Quisiera destacar los méritos innegables de Carmen Luisa Letelier Valdés. Educadora musical de generaciones de cantantes e intérprete notable, cuyo repertorio abarca desde Monteverdi y Bach hasta Debussy y Schoenberg, ha sido permanente difusora, dentro y fuera del país, de nuestros compositores contemporáneos.

Me parece, pues, de justicia haberla premiado y evitar olvidos de otras épocas, que no debieron existir en la concesión del máximo galardón de las Bellas Artes en Chile”. 